\title{
Big-headed marine crocodyliforms and why we must be cautious when using extant species as body length proxies for long-extinct relatives
}

\author{
Mark T. Young, Márton Rabi, Mark A. Bell, Davide Foffa, \\ Lorna Steel, Sven Sachs, and Karin Peyer
}

\begin{abstract}
Body size is commonly used as a key variable for estimating ecomorphological trends at a macroevolutionary scale, making reliable body length estimates of fossil taxa critically important. Crocodylomorphs (extant crocodylians and their extinct relatives) evolved numerous 'aberrant' body-plans during their $\sim 230$ million-year history, ranging from 'hooved' terrestrial species to dolphin-like pelagic species. Such clades evolved distinct cranial and femoral scaling ratios (compared to total body length), thereby making extant taxa unsuitable proxies for estimating their body lengths. Here we illustrate that the fossil clade Teleosauridae also fits into this category. Teleosaurids were a predominately shallow marine clade that had a global distribution during the Jurassic. Known to have evolved a wide range of body lengths (2-5 $\mathrm{m}$ based on complete skeletons), there is currently no way of reliably estimating the size of incomplete specimens. This is surprising, as some teleosaurids have been considered very large (9-10 $\mathrm{m}$ in total length), thus making Teleosauridae the largest bodied clade during the first 100 million years of crocodylomorph evolution. Our examination and regression analyses of the best preserved teleosaurid skeletons demonstrates that: they were smaller than previously thought, with no known specimen exceeding $7.2 \mathrm{~m}$ in length; and that they had proportionally large skulls, and proportionally short femora, when compared to body length. Therefore, while many teleosaurid species evolved a cranial length of $\geq 1 \mathrm{~m}$, these taxa would not necessarily have been larger than species living today. We advise caution when estimating body length for extinct taxa, especially for those outside of the crown group.
\end{abstract}

Mark T. Young. School of GeoSciences, The King's Buildings, University of Edinburgh, James Hutton Road, Edinburgh, EH9 3FE. myoung5@staffmail.ed.ac.uk

Márton Rabi. (1) Department of Earth Sciences, University of Turin, Via Valperga Caluso 35, 10125, Turin, Italy. (2) Institut für Geowissenschaften, University of Tübingen, Hölderlinstraße 12, 72074 Tübingen, Germany. iszkenderun@gmail.com

Mark A. Bell. Department of Earth Sciences, Kathleen-Lonsdale Building, University College London, Gower Street, London, WCIE 6BT. mark.bell521@gmail.com

Davide Foffa. School of GeoSciences, The King's Buildings, University of Edinburgh, James Hutton Road, Edinburgh, EH9 3FE. davidefoffa@gmail.com

Young, Mark T., Rabi, Márto, Bell, Mark A., Foffa, Davide, Steel, Lorna, Sachs, Sven, and Peyer, Karin. 2016. Big-headed marine crocodyliforms and why we must be cautious when using extant species as body length proxies for long-extinct relatives.

Palaeontologia Electronica 19.3.30A: 1-14

palaeo-electronica.org/content/2016/1554-teleosaurid-size-estimation 
Lorna Steel. Department of Earth Sciences, Natural History Museum, Cromwell Road, London, SW7 5BD, United Kingdom. I.steel@nhm.ac.uk

Sven Sachs. Naturkundemuseum Bielefeld, Abteilung Geowissenschaften, Adenauerplatz 2, 33602

Bielefeld, Germany and Im Hof 9, 51766 Engelskirchen, Germany. sachs.pal@gmail.com

Karin Peyer. Département Histoire de la Terre, Muséum National d'Histoire Naturelle, Paris, 8 rue Buffon, CP 38, F-75005, France. karin_peyer@yahoo.fr

Keywords: body length; Mesozoic; Metriorhynchidae; Phenotypic evolution; Teleosauridae

\section{INTRODUCTION}

Body size is an important measure of ecological diversity. This is due to the relationship between body size and a variety of ecological traits directly linked to fitness, such as survival, prey capture, and reproductive success (e.g., Hutchinson and MacArthur, 1959; Damuth, 1981; Peters, 1983; Gaston and Blackburn, 1996; Kozlowski and Gawelczyk, 2002; van Valkenburgh et al., 2004). How body size variation interacts with species richness has long been studied (e.g., Hutchinson and MacArthur, 1959; May, 1988; McClain and Boyer, 2009), with research suggesting that niche subdivision is partially driven by body size differentiation among sympatric species (e.g., McDonald, 2002; Colloca et al., 2010; Young et al., 2011). Body size is also one of the few ecological variables that can be readily measured from fossils for establishing macroevolutionary trends. However, body size estimates in extinct taxa are subject to uncertainty due to incompleteness of fossil specimens, or deviation of their body-plan from that of extant relatives. This particularly applies for taxa that superficially resemble modern morphotypes, which are then used for analogies, instead of investigating actual body proportions.

Teleosaurids were a clade of semi-aquatic crocodylomorphs primarily known from coastal and lagoonal environments during the Jurassic Period (Buffetaut, 1982a; Vignaud, 1995; Hua and Buffetaut, 1997; Young et al., 2014). Most teleosaurids had an elongate tubular rostrum with a high tooth count, dorsolaterally orientated orbits, a transversely expanded premaxilla and anterior dentary, and proportionally enlarged supratemporal fenestrae, thereby leading to an appellation of something akin to 'marine gavials' for the clade (Figures 1-2; Andrews, 1909; Andrews, 1913; Adams-Tresman, 1987; Vignaud, 1995; Hua and Buffetaut, 1997). But, were teleosaurids really just 'marine gavials'? The body-plan of teleosaurids has never been investigated in-depth, and neither is there a reliable method for estimating total body length for incomplete specimens. This is somewhat puzzling given that teleosaurids are considered to be the largest crocodylomorphs of the Jurassic, and perhaps also the earliest part of the Early Cretaceous, with some species estimated to reach $9-10 \mathrm{~m}$ in length (Krebs, 1968; Steel, 1973; Buffetaut, 1982b; Young et al., 2014; Johnson et al., 2015; Fanti et al., 2016). As such, teleosaurids were a key component of coastal, lagoonal and brackish ecosystems during the Jurassic and Early Cretaceous.

While teleosaurids were a diverse and superficially gavial-like clade, within their sister group, Metriorhynchoidea evolved pelagic forms with hypocercal tails, flipper-like limbs, and loss of osteoderm cover (Metriorhynchidae; Figure 2.3). However, the basal-most metriorhynchoid, Pelagosaurus typus Bronn, 1841, had a body-plan superficially similar to Teleosauridae - presence of osteoderms, limbs not modified into flippers, and no regionalisation of the tail (Figure 2.2). Were early metriorhynchoids similarly "gavial-like" in dimensions, prior to evolving the metriorhynchid "dolphin-like" body-plan?

Based on our examination of teleosaurid skeletons and undertaking least-squares linear regression analyses of cranial and femoral lengths against total body length, we demonstrate that Teleosauridae evolved a unique body-plan which had proportionally large crania and short femora. We further demonstrate that using the cranial-tototal body length equations of three extant species, Alligator mississippiensis (Daudin, 1802), Crocodylus porosus Schneider, 1801, and Gavialis gangeticus (Gmelin, 1789) results in significant size overestimates. Additionally, we found that previous body length estimates of teleosaurids are erroneous, as they have overestimated their potential size. Finally, we used teleosaurid and metriorhynchid regression equations to estimate the known body length of Pelagosaurus typus, show- 


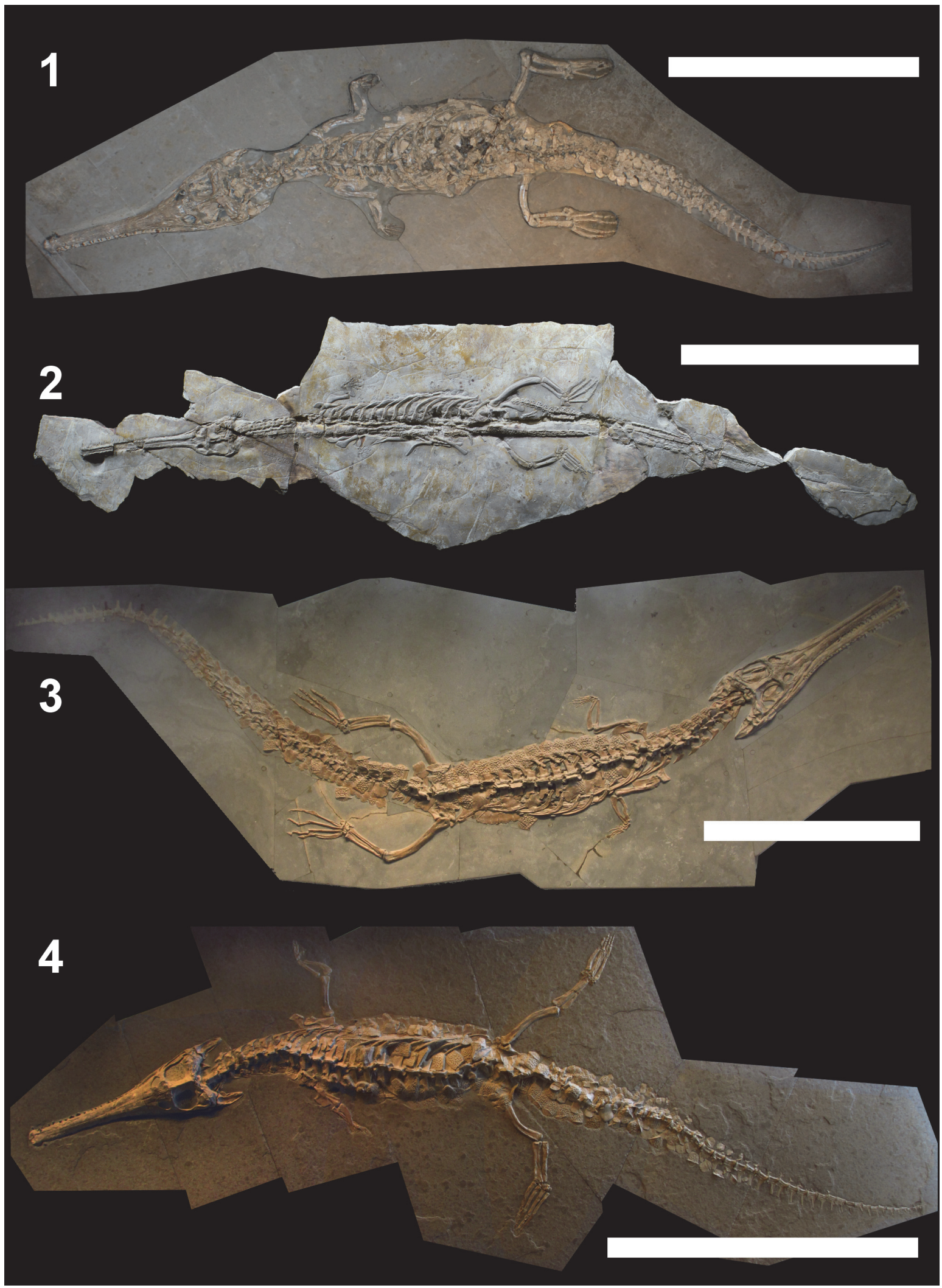

FIGURE 1. Comparative view of four fossil teleosaurid crocodylomorphs used in the regression analyses: (1) Steneosaurus bollensis GPIT/RE/1193/2; (2) Steneosaurus priscus MNHN.F CNJ 78a; (3) Steneosaurus bollensis MH unnumbered A; and (4) Steneosaurus bollensis MH unnumbered B. Scale bars equal $100 \mathrm{~cm}$. 


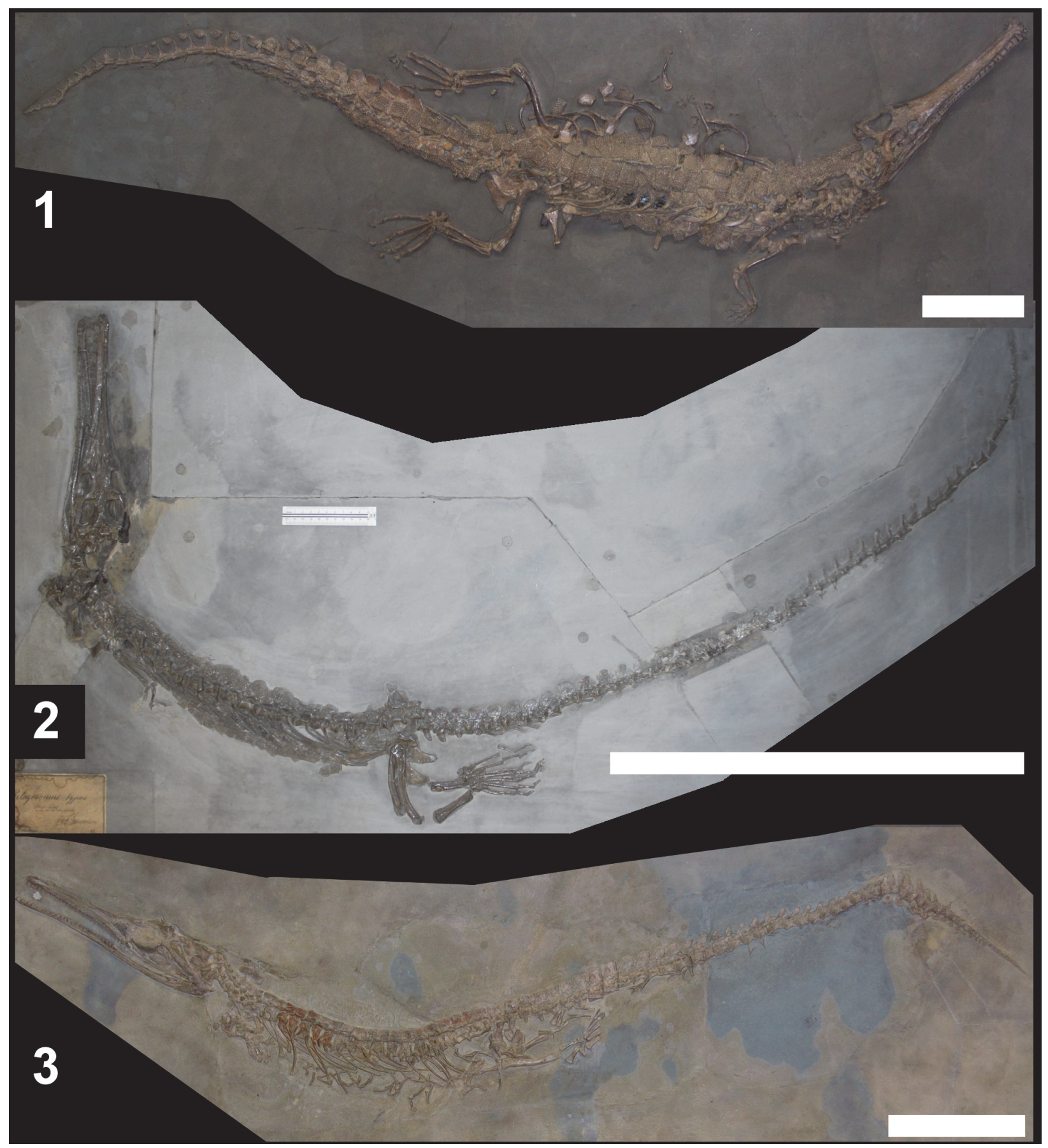

FIGURE 2. Comparative view of three fossil thalattosuchian crocodylomorphs: (1) teleosaurid Platysuchus multiscrobiculatus SMNS 9930; (2) basal metriorhynchoid Pelagosaurus typus MTM M62 2516; and (3) metriorhynchid Cricosaurus suevicus SMNS 9808 . Scale bars equal $50 \mathrm{~cm}$.

ing that the metriorhynchid equation provides the better estimate. We argue for caution when using extant species as body size proxies for long-extinct related clades, as errors can easily be made due to differences in scaling ratios.

\section{MATERIAL AND METHODS}

\section{Institutional Abbreviations}

GPIT/RE, reptile collection of the Paläontologische Sammlung der Eberhard Karls Universität Tübingen, Germany; MH, Urweltmuseum Hauff, Holz- 
maden, Germany; MNHN.F, fossil collection of the Muséum national d'Histoire naturelle, Paris, France (CNJ, Canjuers locality); MTM Magyar Természettudományi Múzeum, Budapest, Hungary; NHMUK PV, vertebrate palaeontology collection of the Natural History Museum, London, United Kingdom (R, reptiles); PETMG, Peterborough Museum and Art Gallery, Peterborough, United Kingdom; SMNS, Staatliches Museum für Naturkunde Stuttgart, Germany.

\section{Morphometric Abbreviations}

$\mathrm{CL}$, cranial length (length from the occipital condyle to the tip of the snout); FL, femoral length (distance from the most proximal point on the proximal articular surface of the bone to the most distal point on the lateral distal condyle); TL, total body length (length from the tip of the snout, to the tip of the tail).

In order to investigate the two most widely used methods of total body length estimation for crocodylomorphs, we used two bivariate leastsquares linear regression analyses, regressing CLTL and FL-TL. The program $R$ served as the statistical platform for this study (R Core Team, 2014). While there are numerous teleosaurid skeletons preserved (in particular from the Toarcian-aged Holzmaden deposits), many of those specimens are lacking most/all of the distal end of the tail (i.e., caudal vertebrae posterior to the terminal caudal osteoderms) and/or have some post-mortem disassociation or distortion. Therefore, we ran two different sets of analyses: firstly, limiting ourselves to the most complete specimens, and secondly using an expanded dataset that included skeletons with the distal-end of the tail missing (approximately 10-20 cm).

During the data gathering phase of this project we attempted to create a third method for estimating body length, using snout basal width (i.e., the snout width immediately anterior to the orbits). This skull measurement was chosen as it was found to be isometric during teleosaurid ontogeny (Vignaud, 1995). Unfortunately, most teleosaurid specimens in our sample were unsuitable due to: dorsoventral compression which exaggerated this measurement; and/or the skull being sheared or preserved obliquely, distorting measurement values. For these reasons we decided to exclude a third body length estimation analysis from this study.

The teleosaurids included in the first regression analysis were 12 large sub-adult and adult specimens pertaining to Platysuchus multiscrobiculatus (Berckhemer, 1929), Steneosaurus bollensis (von Jäger, 1828) (seven individuals), S. edwardsi Eudes-Deslongchamps, 1868 (two individuals), S. leedsi Andrews, 1909, and S. priscus (von Sömmerring, 1814) (Figures. 1, 2.1; Table 1). Our taxon choice covers most of the known teleosaurid fossil record, with species from the Lower Jurassic (Platysuchus multiscrobiculatus and Steneosaurus bollensis), the Middle Jurassic (S. edwardsi and $S$. leedsi), and the Late Jurassic ( $S$. priscus). The second analysis included the first set, plus an additional four specimens that have been referred to Steneosaurus sp. and S. bollensis from the Lower Jurassic of Germany (Table 2). All teleosaurid measurements were recorded first-hand by MTY, MR, LS, SS, DF, and KP. In order to determine the scaling ratios of Pelagosaurus typus, MR measured the two most complete skeletons of this species known to us (Table 3 ).

\section{RESULTS}

\section{Cranial Length versus Total Body Length}

Least-squares regression analysis for CL-TL using the 12 most complete teleosaurid specimens resulted in a highly statistically significant correlation $\left(y=4.016 x+92.317, R^{2}=0.9315, P\right.$ (permutation) $=0.0001$ ) (Figure 3.1). The teleosaurid CL-TL equation is noticeably different from those of extant species reported by Young et al. (2011) (based on data from Woodward et al., 1995; Sereno et al., 2001): Crocodylus porosus ( $y=7.696 x-18.914$, $\left.R^{2}=0.990, P<0.0001\right)$, Gavialis gangeticus $(y=$ 7.416x - 63.212, $\left.R^{2}=0.991, P<0.0001\right)$, and Alligator mississippiensis $\left(y=7.127 x+9.478, R^{2}=\right.$ $0.995, P<0.0001)$. Thus demonstrating, that although teleosaurids are often considered 'marine gavials', their cranial-to-body length scaling ratio is distinctly different (Figure 4). When the extant taxa CL-TL equations were used to calculate teleosaurid body length estimates, the differences were notable (Table 4). With increasing cranial length, the divergence becomes more extreme, such as the two $\sim 5 \mathrm{~m}$ long Steneosaurus edwardsi specimens being estimated as $7.6 \mathrm{~m}$ and $8.2 \mathrm{~m}$ when using the Crocodylus equation (Table 4). Even using the longirostrine Gavialis as a proxy results in a large overestimate, with these specimens estimated as $6.93 \mathrm{~m}$ and $7.45 \mathrm{~m}$ long, respectively.

The only (very slight) underestimate was obtained when using the Gavialis CL-TL equation for Platysuchus multiscrobiculatus. This outcome is unique to Platysuchus, and not related to total length as the complete Steneosaurus bollensis 
TABLE 1. Measurements of the teleosaurid specimens used in the first set of regression analyses (i.e. the most complete skeletons). All measurements in $\mathrm{cm}$.

\begin{tabular}{|c|c|c|c|}
\hline Specimen & Femoral length & Cranial length & Total body length \\
\hline $\begin{array}{l}\text { Platysuchus multiscrobiculatus } \\
\text { SMNS } 9930\end{array}$ & 20 & 45.5 & 279 \\
\hline $\begin{array}{l}\text { Steneosaurus bollensis } \\
\text { GPIT/RE/1193/2 }\end{array}$ & 34 & 78.5 & 461 \\
\hline $\begin{array}{l}\text { Steneosaurus bollensis } \\
\text { MH unnumbered A }\end{array}$ & 36 & 91 & 477 \\
\hline $\begin{array}{l}\text { Steneosaurus bollensis } \\
\text { MH unnumbered B }\end{array}$ & 24 & 59.5 & 312 \\
\hline $\begin{array}{l}\text { Steneosaurus bollensis } \\
\text { SMNS } 54063\end{array}$ & 30.5 & 78 & 430 \\
\hline $\begin{array}{l}\text { Steneosaurus bollensis } \\
\text { SMNS } 52475\end{array}$ & 21.9 & 52.5 & 304 \\
\hline $\begin{array}{l}\text { Steneosaurus bollensis } \\
\text { SMNS } 51984\end{array}$ & 22.5 & 59 & 320 \\
\hline $\begin{array}{l}\text { Steneosaurus bollensis } \\
\text { MTM unnumbered }\end{array}$ & 18.1 & 48 & 278 \\
\hline $\begin{array}{l}\text { Steneosaurus edwardsi } \\
\text { GPIT/RE/07286 }\end{array}$ & 39 & 102 & 502 \\
\hline $\begin{array}{l}\text { Steneosaurus edwardsi } \\
\text { PETMG R175 }\end{array}$ & 40.5 & 109 & 501.5 \\
\hline $\begin{array}{l}\text { Steneosaurus leedsi } \\
\text { NHMUK PV R } 3806\end{array}$ & 29.8 & 88 & 428 \\
\hline $\begin{array}{l}\text { Steneosaurus priscus } \\
\text { MNHN.F CNJ 78a }\end{array}$ & 25 & 68.3 & 347 \\
\hline
\end{tabular}

specimen measuring less than $3 \mathrm{~m}$ was overestimated in size (Table 4).

The CL-TL teleosaurid equation also differs from its sister taxon Metriorhynchidae $(y=5.506 x$ 8.162, $R^{2}=0.997, P<0.001$; Young et al., 2011). While a difference was anticipated (as metriorhynchids were pelagic taxa with hypocercal tails and flipper-like limbs), it was not expected that teleosaurids would have proportionally longer crania in relation to total body length.

Least-squares regression analysis for CL-TL using all 16 teleosaurid specimens also resulted in a statistically significant correlation $(y=4.139 x+$ 76.871, $R^{2}=0.9236, P$ (permutation) $\left.=0.0001\right)$

TABLE 2. Measurements of the teleosaurid specimens added to the second set of regression analyses (i.e., the skeletons lacking at least $10-20 \mathrm{~cm}$ of the distal tail). All measurements in $\mathrm{cm}$.

\begin{tabular}{lccc}
\hline \multicolumn{1}{c}{ Specimen } & Femoral length & Cranial length & Total body length \\
\hline $\begin{array}{l}\text { Steneosaurus sp. } \\
\text { SMNS 51753 }\end{array}$ & 24 & 66 & 312 \\
$\begin{array}{l}\text { Steneosaurus bollensis } \\
\text { SMNS 51555 }\end{array}$ & 22 & 63.5 & 306.5 \\
$\begin{array}{l}\text { Steneosaurus bollensis } \\
\text { SMNS 51957 }\end{array}$ & 27 & 59 & 311 \\
$\begin{array}{l}\text { Steneosaurus bollensis } \\
\text { SMNS uncatalogued }\end{array}$ & 13.5 & 35.5 & 227.5 \\
\hline
\end{tabular}

TABLE 3. Measurements of the Pelagosaurus typus specimens. All measurements in $\mathrm{cm}$.

\begin{tabular}{lccc}
\hline Specimen & Femoral length & Cranial length & Total body length \\
\hline SMNS 51753 & 17.5 & 42 & 233.5 \\
MTM M62 2516 & 11.1 & 27.5 & 145 \\
\hline
\end{tabular}


(1)

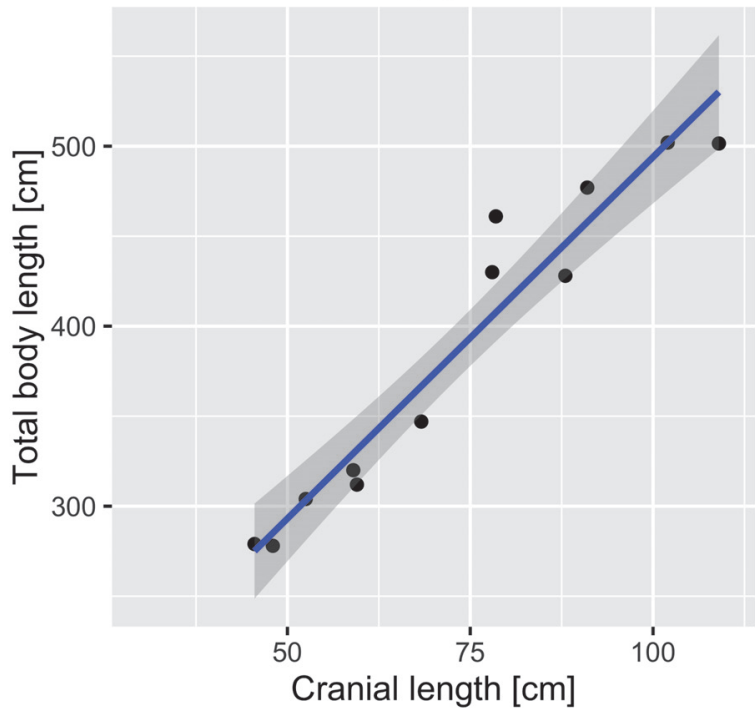

(3)

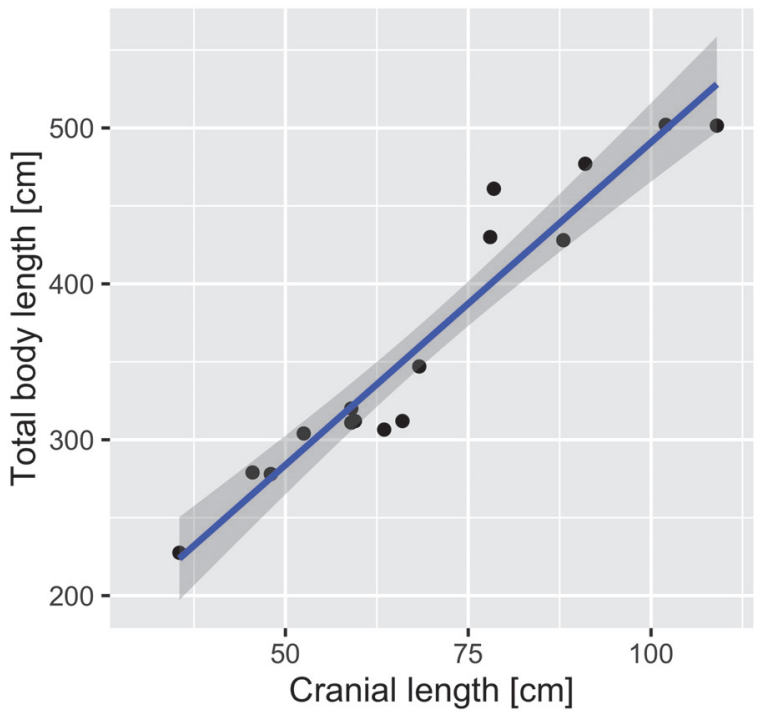

(2)

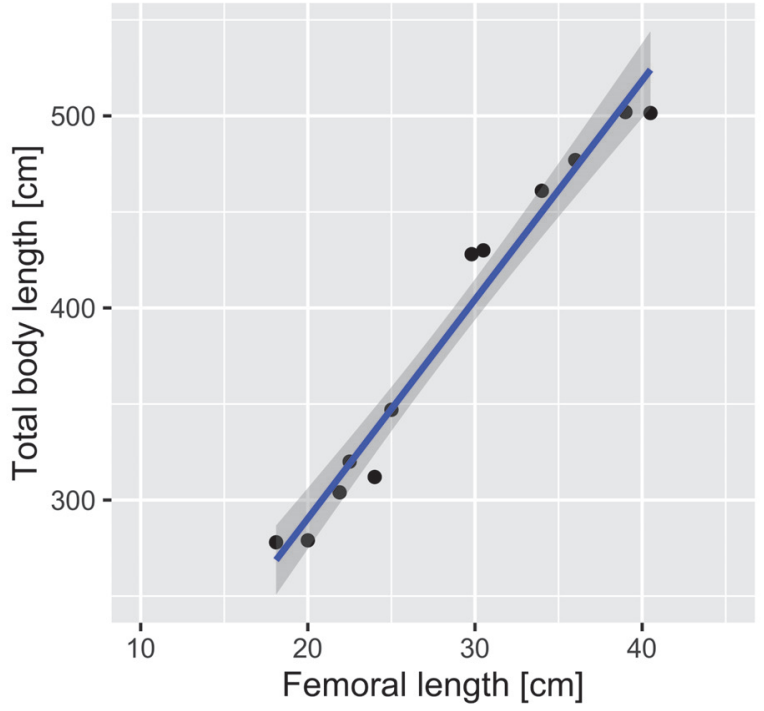

(4)

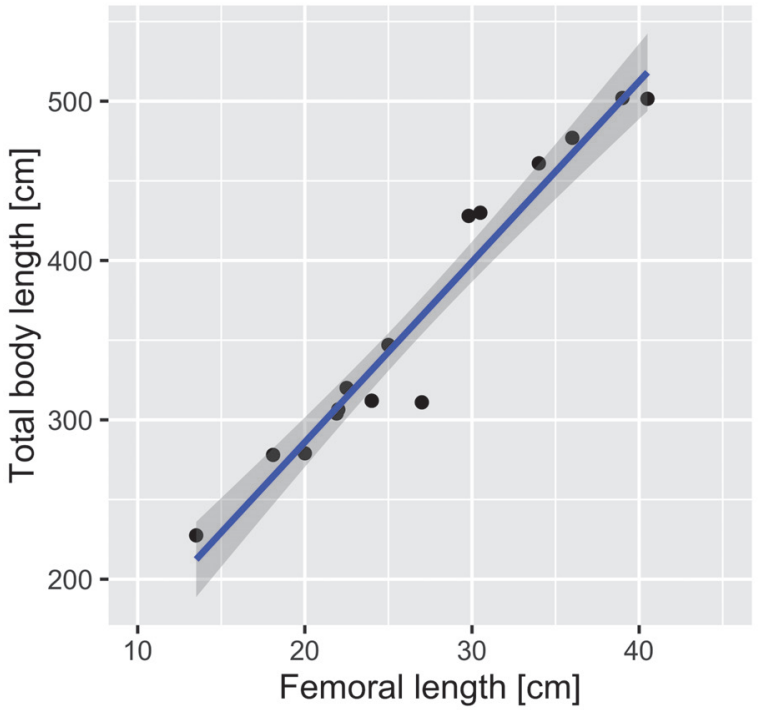

FIGURE 3. Bivariate plots of cranial $(1,3)$ and femoral lengths $(2,4)$ plotted against total lengths for complete specimens only $(1,2)$ and for all specimens $(3,4)$. In each case a line of least-squares regression is fitted along with a shaded area representing the confidence interval around the regression model.

(Figure 3.3). The differences between these two equations are minor, and using them to estimate the total body length of the 12 most complete specimens results in only slight estimation differences (by up to $10 \mathrm{~cm}$, Table 5).

\section{Femoral Length versus Total Body Length}

Least-squares regression analysis for FL-TL using the 12 most-complete teleosaurid specimens resulted in a statistically significant correlation $(y=$ $11.40 x+62.46, R^{2}=0.9696, P$ (permutation) $=$ 0.0001) (Figure 3.2). When compared to the FL-TL equation of metriorhynchids, the same significant difference is apparent $\left(y=12.693 x+25.817, R^{2}=\right.$ $0.966, P=0.0076$; Young et al., 2011). Oddly, compared to metriorhynchids, teleosaurids had proportionally shorter femora (as a proportion of total body length). It is currently unclear whether teleosaurids have a reduced femoral length, metriorhynchids elongated their femora, or if there is some combination of the two.

Least-squares regression analysis for FL-TL using all 16 teleosaurid specimens also resulted in a statistically significant correlation $(y=11.32 x+$ 


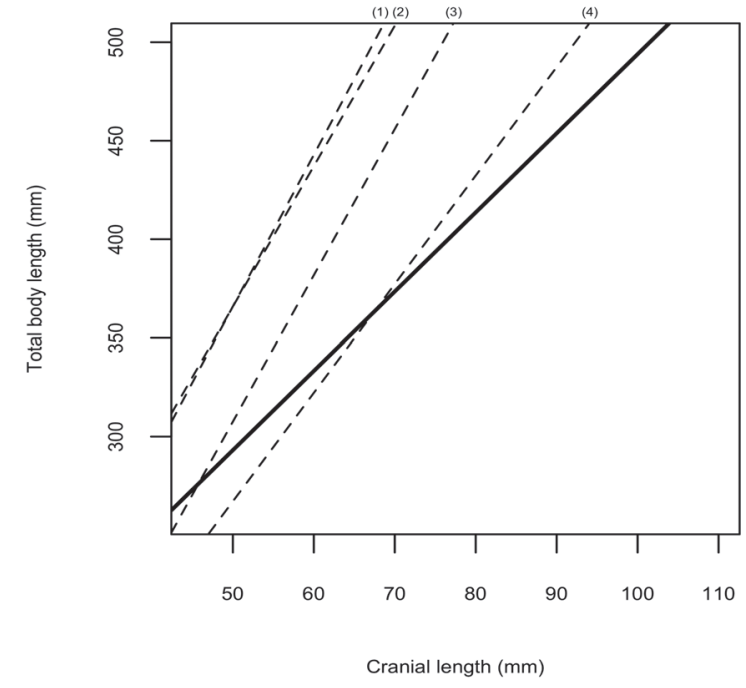

FIGURE 4. Comparative least-squares regression gradient plot, of cranial length-to-total length, with the solid line representing Teleosauridae, and the dashed lines representing (1) Crocodylus, (2) Alligator, (3) Gavialis, and (4) Metriorhynchidae, respectively.
$59.55, R^{2}=0.9458, P$ (permutation $\left.)=0.0001\right)($ Figure 3.4). As with the cranial analyses, the differences between the complete and incomplete specimen equations is minor, and using them to estimate the total body length of the twelve most complete specimens results in only slight length estimation differences (again, by up to $10 \mathrm{~cm}$, Table 5).

\section{Comparison of Teleosaurid Regression Models}

The fit of each of the two regression models (CL-TL and FL-TL) across both datasets, including all specimens and the reduced dataset with only the most complete specimens, were assessed using a maximum likelihood approach. For each of the four models the bias-corrected form of the Akaike Information Criterion was calculated using the AICc function available in the qpcR package (Ritz and Spiess, 2008) for R (R Core Team, 2014). These AICc values were then transformed into a weighted value representing the probability of the model; here this is performed independently for the

TABLE 4. The 12 most complete teleosaurid specimens used in the regression analyses, with their recorded lengths and estimated lengths using the cranial-total body length equations of three extant species (Alligator mississippiensis, Crocodylus porosus, and Gavialis gangeticus). All measurements in $\mathrm{cm}$.

\begin{tabular}{lcccc}
\hline \multicolumn{1}{c}{ Specimen } & Measured length & $\begin{array}{c}\text { Crocodylus } \\
\text { equation }\end{array}$ & $\begin{array}{c}\text { Gavialis } \\
\text { equation }\end{array}$ & $\begin{array}{c}\text { Alligator } \\
\text { equation }\end{array}$ \\
\hline $\begin{array}{l}\text { Platysuchus multiscrobiculatus } \\
\text { SMNS 9930 }\end{array}$ & 279 & 331.3 & 274.2 & 333.8 \\
$\begin{array}{l}\text { Steneosaurus bollensis } \\
\text { GPIT/RE/1193/2 }\end{array}$ & 461 & 585.2 & 518.9 & 568.9 \\
$\begin{array}{l}\text { Steneosaurus bollensis } \\
\text { MH unnumbered A }\end{array}$ & 477 & 681.4 & 611.6 & 658.0 \\
$\begin{array}{l}\text { Steneosaurus bollensis } \\
\text { MH unnumbered B }\end{array}$ & 312 & 439.0 & 378.0 & 433.5 \\
$\begin{array}{l}\text { Steneosaurus bollensis } \\
\text { SMNS 54063 }\end{array}$ & 430 & 581.4 & 515.2 & 565.4 \\
$\begin{array}{l}\text { Steneosaurus bollensis } \\
\text { SMNS 52475 }\end{array}$ & 304 & 385.1 & 326.1 & 383.6 \\
$\begin{array}{l}\text { Steneosaurus bollensis } \\
\text { SMNS 51984 }\end{array}$ & 320 & 435.1 & 374.3 & 423.0 \\
$\begin{array}{l}\text { Steneosaurus bollensis } \\
\text { MTM unnumbered }\end{array}$ & & & & \\
$\begin{array}{l}\text { Steneosaurus edwardsi } \\
\text { GPIT/RE/07286 }\end{array}$ & 278 & 350.5 & 292.8 & 351.6 \\
$\begin{array}{l}\text { Steneosaurus edwardsi } \\
\text { PETMG R175 }\end{array}$ & 502 & 766.1 & 693.2 & 736.4 \\
$\begin{array}{l}\text { Steneosaurus leedsi } \\
\text { NHMUK PV R 3806 }\end{array}$ & 501.5 & 820.0 & 745.1 & 786.3 \\
$\begin{array}{l}\text { Steneosaurus priscus } \\
\text { MNHN.F CNJ 78a }\end{array}$ & 428 & 658.3 & 589.4 & 636.7 \\
\hline
\end{tabular}


TABLE 5. Estimated body lengths for the 12 most complete teleosaurid specimens used in the regression analyses. All four regression equations generated herein are compared against specimen recorded total lengths. All measurements in $\mathrm{cm}$.

\begin{tabular}{|c|c|c|c|c|c|}
\hline \multirow[b]{2}{*}{ Specimen } & \multirow{2}{*}{$\begin{array}{l}\text { Total body } \\
\text { length }(\mathrm{cm})\end{array}$} & \multicolumn{4}{|c|}{ Total body length estimates $(\mathrm{cm})$} \\
\hline & & CL complete & $\begin{array}{c}\mathrm{CL} \\
\text { incomplete }\end{array}$ & FL complete & FL incomplete \\
\hline $\begin{array}{l}\text { Platysuchus multiscrobiculatus } \\
\text { SMNS } 9930\end{array}$ & 279 & 275.05 & 265.20 & 290.46 & 285.95 \\
\hline $\begin{array}{l}\text { Steneosaurus bollensis } \\
\text { GPIT/RE/1193/2 }\end{array}$ & 461 & 407.57 & 401.78 & 450.067 & 444.43 \\
\hline $\begin{array}{l}\text { Steneosaurus bollensis } \\
\text { MH unnumbered } \mathrm{A}\end{array}$ & 477 & 457.77 & 453.52 & 472.86 & 467.07 \\
\hline $\begin{array}{l}\text { Steneosaurus bollensis } \\
\text { MH unnumbered B }\end{array}$ & 312 & 331.27 & 323.14 & 336.06 & 331.23 \\
\hline $\begin{array}{l}\text { Steneosaurus bollensis } \\
\text { SMNS } 54063\end{array}$ & 430 & 405.57 & 399.71 & 410.16 & 404.81 \\
\hline $\begin{array}{l}\text { Steneosaurus bollensis } \\
\text { SMNS } 52475\end{array}$ & 304 & 303.16 & 294.17 & 312.12 & 307.46 \\
\hline $\begin{array}{l}\text { Steneosaurus bollensis } \\
\text { SMNS } 51984\end{array}$ & 320 & 329.26 & 321.07 & 318.96 & 314.25 \\
\hline $\begin{array}{l}\text { Steneosaurus bollensis } \\
\text { MTM unnumbered }\end{array}$ & 278 & 285.09 & 275.54 & 268.80 & 264.44 \\
\hline $\begin{array}{l}\text { Steneosaurus edwardsi } \\
\text { GPIT/RE/07286 }\end{array}$ & 502 & 501.95 & 499.05 & 507.06 & 501.03 \\
\hline $\begin{array}{l}\text { Steneosaurus edwardsi } \\
\text { PETMG R175 }\end{array}$ & 501.5 & 530.06 & 528.02 & 524.16 & 518.01 \\
\hline $\begin{array}{l}\text { Steneosaurus leedsi } \\
\text { NHMUK PV R } 3806\end{array}$ & 428 & 445.73 & 441.10 & 402.18 & 396.89 \\
\hline $\begin{array}{l}\text { Steneosaurus priscus } \\
\text { MNHN.F CNJ 78a }\end{array}$ & 347 & 366.61 & 359.56 & 347.46 & 342.55 \\
\hline
\end{tabular}

two datasets. Regardless of which dataset is being used, femoral length when modelled against total length is the preferred model over the use of cranial length (Table 6).

\section{Comparison of Regression Equations for Pelagosaurus Typus}

Due to the unfortunately small sample size of Pelagosaurus typus specimens $(n=2)$, we could only compare the various thalattosuchian regression equations estimates with known body lengths. For the larger of the two specimens (SMNS 51753), the over- and under-estimates provided by using the teleosaurid and metriorhynchid regression CL-TL equations are largely comparable (Table 7).The femoral length the metriorhynchid FL-TL equation and the 16-taxon cranial length teleosaurid CL-TL equation provide the best fit. It is with the smaller specimen that the differences become apparent. In MTM M62 2516 the metriorhynchid CL-TL and FL-TL equations give the closest approximation to actual body length (Table 7).
Using any of the teleosaurid equations yields a noticeable overestimate, between $29.9-39.8 \%$. While the sample size is small, there is tentative evidence to suggest Pelagosaurus typus had metriorhynchid-like scaling ratios.

\section{DISCUSSION}

\section{Body Length Equations}

Surprisingly, the difference in body length estimation between the complete and incomplete datasets is very limited (see above; Tables 5 and 8 ). A possible explanation is that all the specimens are incomplete, and the expanded dataset only includes specimens where the loss of the distal tail is more noticeable. Alternatively, the missing distal portion of the tail of the incomplete specimens was not as extensive as originally thought.

The maximum likelihood approach shows that when femoral length is modelled against total length, it is the preferred model when compared to cranial length (Table 6). A posteriori, this is perhaps 
TABLE 6. Statistics for the results of the regression analyses comparing the fit of both the cranial and femoral lengths with the total body length, conducted individually for complete specimens only and for all specimens. The best fitting model is highlighted in bold.

\begin{tabular}{llcccccc}
\hline \multicolumn{1}{c}{ Dataset } & \multicolumn{1}{c}{ Model } & Multiple & Adjusted & \multirow{2}{*}{ AIC } & \multirow{2}{*}{$\begin{array}{c}\text { AICc } \\
\mathbf{R}^{2}\end{array}$} & $\begin{array}{c}\text { AICc } \\
\text { weight }\end{array}$ \\
\hline Complete & Total length $\sim$ Cranial length & 0.9315 & 0.9247 & $<0.0001$ & 114.3449 & 115.6783 & 0.0075 \\
specimens & Total length $\sim$ Femoral length & 0.9696 & 0.9666 & $<0.0001$ & 104.5866 & 105.92 & $\mathbf{0 . 9 9 2 5}$ \\
\hline \multirow{2}{*}{ All specimens } & Total length $\sim$ Cranial length & 0.9236 & 0.9182 & $<0.0001$ & 152.9013 & 153.8244 & 0.0603 \\
& Total length $\sim$ Femoral length & 0.9548 & 0.9478 & $<0.0001$ & 146.5062 & 148.5062 & $\mathbf{0 . 9 3 9 7}$ \\
\hline
\end{tabular}

TABLE 7. Estimated body lengths for the two Pelagosaurus typus specimens measured herein. All six thalattosuchian regression equations are compared against specimen recorded total lengths. All measurements in $\mathrm{cm}$.

\begin{tabular}{lccccccc}
\hline \multirow{2}{*}{ Specimen } & \multirow{2}{*}{$\begin{array}{c}\text { Total body } \\
\text { length }\end{array}$} & \multicolumn{2}{c}{$\mathbf{1 2}$ complete teleosaurids } & \multicolumn{2}{c}{ All 16 teleosaurids } & \multicolumn{2}{c}{ Metriorhynchids } \\
\cline { 3 - 9 } & & CL & FL & CL & FL & CL & FL \\
\hline SMNS 51753 & 233.5 & 256.97 & 261.96 & 246.57 & 257.65 & 217.58 & 247.94 \\
MTM M62 2516 & 145 & 202.76 & 189.00 & 190.69 & 185.20 & 143.25 & 166.71 \\
\hline
\end{tabular}

TABLE 8. Estimated body lengths for large-bodied brevirostrine/mesorostrine teleosaurids, namely species in the genus Machimosaurus, and Steneosaurus edwardsi and S. obtusidens. All measurements in $\mathrm{cm}$. Measurements in bold are estimates and/or based on reconstructed elements.

\begin{tabular}{llcc}
\hline \multicolumn{1}{c}{ Species } & \multicolumn{1}{c}{ Cranial or femoral length } & \multicolumn{2}{c}{ Total body length estimate } \\
\cline { 3 - 4 } & & $\begin{array}{c}\text { Complete } \\
\text { skeletons }\end{array}$ & $\begin{array}{c}\text { Including } \\
\text { incomplete tails }\end{array}$ \\
\hline Machimosaurus rex (holotype) & $\mathbf{1 5 5}$ (CL; Fanti et al., 2016) & 714.80 & 718.42 \\
Machimosaurus hugii & $\mathbf{1 4 9}$ (CL; Krebs, 1968) & 690.70 & 693.58 \\
Machimosaurus mosae (holotype) & $\mathbf{1 3 0}$ (CL; Sauvage and Liénard, 1879) & 614.40 & 614.94 \\
Machimosaurus mosae (neotype) & $\mathbf{9 6 . 5}$ (CL; Hua, 1999) & 479.86 & 476.28 \\
Machimosaurus buffetauti & $\mathbf{1 0 0 ~ ( C L ; ~ B u f f e t a u t , ~ 1 9 8 2 b ) ~}$ & 493.92 & 490.77 \\
Machimosaurus buffetauti (holotype) & 93.5 (CL; Young et al., 2014) & 467.81 & 463.87 \\
Steneosaurus edwardsi & 53 (FL; Johnson et al., 2015) & 666.66 & 659.51 \\
Steneosaurus obtusidens (holotype) & 116 (CL; Andrews, 1913) & 558.17 & 556.00 \\
\hline
\end{tabular}

unsurprising given that teleosaurids evolved a wide range of snout lengths, with longirostrine (Platysuchus multiscrobiculatus, Steneosaurus bollensis, S. leedsi, and S. priscus) and mesorostrine species (S. edwardsi and S. obtusidens). Unfortunately, brevirostrine Machimosaurus species could not be included in the analyses as all known specimens preserve less than half of the caudal vertebral column (i.e., as in the Machimosaurus mosae Sauvage and Liénard, 1879 neotype skeleton; Hua, 1999). These snout classifications are based on the ratio of preorbital length to cranial length, with longirostry being a ratio of $\geq 70 \%$, mesorostry being between $55-70 \%$, and brevirostry is $<55 \%$. Therefore, as there is a variation in snout length of $\geq 15 \%$ within Teleosauridae, it is possible that this is why the femoral equations are the better fit. Although, within a sub-clade of teleosaurids there is a trend of anteroposteriorly elongating the supratemporal fenestrae (i.e., Callovian-Tithonian
'Steneosaurus' species and Machimosaurus; Andrews, 1913; Vignaud, 1995; Young et al., 2014; Fanti et al., 2016), which might be another contributing factor. Thus, both preorbital and postorbital lengths are subject to macroevolutionary trends in Teleosauridae.

\section{Teleosaurid Body Length Estimation}

With the resultant regression equations, we can attempt to estimate the body lengths of the largest teleosaurids. However, two points must be noted: firstly, this involves extrapolation - i.e., predicting total body lengths greater than the range of the specimens used for the regression analyses; and secondly, the lack of brevirostrine specimens in the sample. As such these estimates should be treated as preliminary, until complete Machimosaurus skeletons can be added to this sample. That being said, our sample does include two specimens of the large-bodied mesorostrine species 
Steneosaurus edwardsi, the sister taxon to the blunt-toothed durophagous teleosaurid sub-clade (Young et al., 2012), and both specimens have skulls greater than $1 \mathrm{~m}$ in length. With these caveats, it is noted that the 'gigantic' species are not estimated to be as large as previously supposed (e.g., Krebs, 1968; Steel, 1973; Buffetaut, 1982b; Young et al., 2014; Johnson et al., 2015; Fanti et al., 2016). The 'gigantic' size estimates of between 9.0-9.5 m for Machimosaurus hugii (Krebs, 1968; Steel, 1973; Young et al., 2014) and $10.0 \mathrm{~m}$ for $M$. rex Fanti et al., 2016 are not supported. Our regression equations yield smaller estimates of approximately $6.9 \mathrm{~m}$ and $7.15 \mathrm{~m}$, respectively (Table 8; Figure 5). Moreover, the largest known Middle Jurassic crocodylomorph, Steneosaurus edwardsi, is estimated to be around $6.6 \mathrm{~m}$ long, and not approximately $7 \mathrm{~m}$ long (as in Johnson et al., 2015). Note that the $M$. mosae body length used in Young et al. (2014), Johnson et al. (2015), and Fanti et al. (2016) were incorrect, as they added cranial length to the reported body length measurement of Hua (1999). Thus, the erroneous total body length measurement given in Young et al. (2014) resulted in an overestimation of these taxa.

Although many teleosaurid species evolved a skull length of $\geq 1 \mathrm{~m}$ (e.g. Andrews, 1913; Krebs, 1968; Buffetaut, 1982b; Vignaud, 1995; Young et al., 2014; Fanti et al., 2016), their corresponding body lengths were not greater than those seen in large extant crocodylomorph taxa. Therefore teleosaurids, like metriorhynchids, evolved proportionally large skulls relative to their body length. Thus it would appear that the evolution of proportionally large skulls occurred early in thalattosuchian evolution and prior to the teleosaurid-metriorhynchid split, and may have been an adaptive response to living in a marine environment. It would be interesting to explore whether other marine crocodylomorph lineages also underwent this macroevolutionary trend.

While our regression analyses result in significantly smaller body length estimates for teleosaurids, they still would have been the largest crocodylomorphs of the Jurassic. The largest known crocodylomorph of the Early Jurassic was Steneosaurus bollensis ( $>5 \mathrm{~m}$; Westphal, 1962), in the Middle Jurassic it was $S$. edwardsi $(6.6 \mathrm{~m})$, and during the Late Jurassic it was Machimosaurus hugii $(\sim 6.9 \mathrm{~m})$ (Figure 5). Currently it is unclear whether Machimosaurus rex $(\sim 7.15 \mathrm{~m})$ was the largest crocodylomorph of the pre-Aptian Early Cretaceous, as the ages and body sizes of the

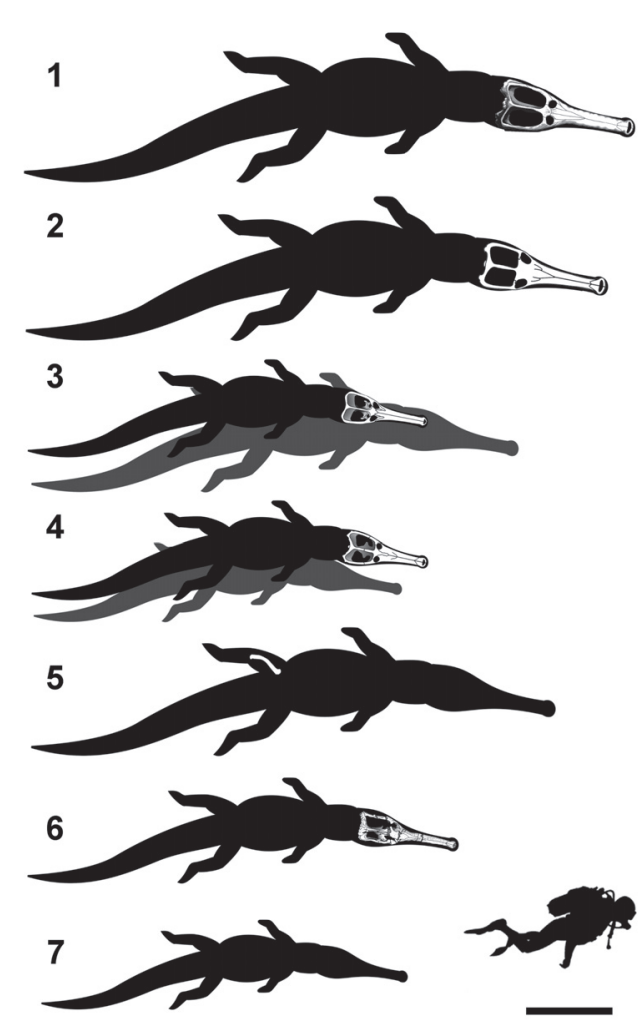

FIGURE 5. Comparative view of estimated body length of large-bodied teleosaurids (see Table 8). (1) Machimosaurus rex (holotype); (2) Machimosaurus hugii (referred specimen from Krebs, 1968); (3) Machimosaurus mosae (neotype, grey silhouette is the lost holotype); (4) Machimosaurus buffetauti (holotype, grey silhouette is the specimen from Buffetaut, 1982b); (5) Steneosaurus edwardsi (referred specimen from Johnson et al., 2015); (6) Steneosaurus obtusidens (holotype); (7) Steneosaurus bollensis (based on $\mathrm{MH}$ unnumbered $\mathrm{A}$ ). The skull drawings are modified from (Fanti et al., 2016 and Young et al., 2014). Scale bar equals $1 \mathrm{~m}$.

giant pholidosaurids Sarcosuchus hartti (Marsh, 1869) and Chalawan thailandicus (Buffetaut and Ingavat, 1980) are uncertain.

\section{CONCLUSIONS}

Herein we show that the teleosaurid bodyplan was unique. They had, relative to total body length, proportionally large crania and proportionally short femora. Not only were they distinct from extant taxa, but also from their pelagic sister taxon Metriorhynchidae. As such, they cannot be characterised as 'marine gavials', as they evolved an unusual body-plan that makes using extant proxies for body length estimation unsuitable. Thus, we add Teleosauridae to the growing list of crocodyli- 
forms that evolved scaling ratios distinct from extant crocodylians (Farlow et al., 2005; Young et al., 2011; Pol et al., 2012; Godoy et al., 2016).

The differences in teleosaurid crania and femora proportions when compared to Metriorhynchidae are intriguing. It is currently unclear why a predominately coastal/lagoonal clade like Teleosauridae would have taxa with proportionally larger skulls and shorter femora than a pelagic clade that was common in open-shelf environments. It perhaps suggests that teleosaurids were more aquatically adapted than previously thought. More research into this tantalising possibility is required. Another possibility is that no well-preserved teleosaurid skeleton is actually as complete as we currently think. Perhaps, teleosaurids evolved an elongate distal tail with very small, short caudal vertebrae. This would, however, not explain why the Holzmaden skeletons (which are preserved in the Posidonia oil-shale; Figures 1.1, 1.3, 1.4, 2.1) do not show such an elongated terminal caudal series of vertebrae.

There is tentative evidence to suggest that the basal-most metriorhynchoid, Pelagosaurus typus, had metriorhynchid-like scaling ratios. If this can be supported with larger sample sizes in future studies, it would: 1) further highlight that we cannot use superficially similar taxa as proxies for body length, 2) demonstrate that after teleosaurids and metriorhynchoids split, they may have retained a similar looking body-plan but quickly evolved very distinct scaling ratios, and 3) lend further support for the close affinity of $P$. typus and metriorhynchids (e.g., Buffetaut, 1980; Vignaud, 1995; Young et al., 2012; Wilberg, 2015; Fanti et al., 2016; contra Clark, 1994; Pierce and Benton, 2006; Young and Andrade, 2009). It could be that the evolutionary pressures that resulted in teleosaurids becoming adapted for lagoonal/coastal ecosystems, and metriorhynchoids for open-sea pelagic environments, were acting upon even the earliest members of these clades.

Maximum likelihood modelling supports the use of femoral length, rather than cranial length, as the metric for estimating total body length. The variation in teleosaurid snout length relative to cranial length, of $\geq 15 \%$, is possibly why the femoral equations are a better fit (as is the elongation of the supratemporal fenestrae and the resultant proportional increase in post-orbital length). Our preference for basal snout width rather than cranial length as the method for length estimation could not be realised due to the dorsoventral deformation and/or shearing of the fossil sample skulls. Finally, our results further highlight how extant proxies are unsuitable for long-extinct related subclades, especially with new data from complete skeletons. Until now, data from complete skeletons was scarce and teleosaurids were not generally considered to have had a body-plan that deviated from the norm of extant crocodylians (although see Hua, 1999; Farlow et al., 2005). As such, we argue caution when using extant crocodylian regression equations for any taxon not considered to be a semi-aquatic eusuchian, and more generally for taxa that are not part of a crown group.

\section{ACKNOWLEDGEMENTS}

We would like to thank P. Hurst (NHMUK Image Resources), L. Cazes (MNHN), and $\mathrm{M}$. Szabó (MTM) for specimen photography, R. Allain (MNHN), R. Schoch (SMNS), R. Hauff (MH), H. Stöhr (GPIT), and G. Wass (PETMG) for collections access. We also thank the two anonymous reviewers for their constructive comments. MTY received support for his collection visits to Paris (FR-TAF4021) and Stuttgart (DE-TAF-5132) from the SYNTHESYS Project (www.synthesys.info/), which is financed by European Community Research Infrastructure Action under the FP7 "Capacities" Program. MR was supported by a Marie CurieTrain2Move fellowship.

\section{REFERENCES}

Adams-Tresman, S.M. 1987. The Callovian (Middle Jurassic) teleosaurid marine crocodiles from Central England. Palaeontology, 30:195-206.

Andrews, C.W. 1909. On some new Steneosaurs from the Oxford Clay of Peterborough. Annals and Magazine of Natural History, eighth series, 3:299-308.

Andrews, C.W. 1913. A descriptive catalogue of the marine reptiles of the Oxford Clay, Part Two. British Museum (Natural History), London.

Berckhemer, F. 1929. Beiträge zur Kenntnis der Krokodilier des schwäbischen oberen Lias. Neues Jahrbuch für Mineralogie, Geologie und Paläontologie, Beilagenband 64B:1-59.

Bronn, H.G. 1841. Untersuchung zweier Gavial-Skelette und der Gaumen zweier andern aus den Boller LiasSchiefen, mit Rücksicht auf Geoffroy's Genus Teleosaurus, p. 5-30. In Bronn, H.G. and Kaup, J.J. (eds.), Abhandlungen über die Gavial-artigen Reptilien der Lias-Formation. E. Schweizerbart'sche Verlagshandlung, Stuttgart.

Buffetaut, E. 1980. Position systématique et phylogénetique du genre Pelagosaurus Bronn, 1841 (Crocodylia, Mesosuchia), du Toarcian d'Europe. Geobios, 13:783-786. 
Buffetaut, E. 1982a. Radiation évolutive, paléoécologie et biogéographie des crocodiliens mésosuchiens. Mémoires de la Société Géologique de France, 60:1-88.

Buffetaut, E. 1982b. Le crocodilien Machimosaurus VON MEYER (Mesosuchia, Teleosauridae) dans le Kimmeridgien de l'Ain. Bulletin trimestriel de la Société Géologique de Normandie et des Amis du Muséum du Havre, 69:17-27.

Buffetaut, E. and Ingavat, R. 1980. A new crocodilian from the Jurassic of Thailand, Sunosuchus thailandicus n. sp. (Mesosuchia, Goniopholididae), and the palaeogeographical history of South-East Asia in the Mesozoic. Geobios, 13:879-889.

Clark, J.M. 1994. Patterns of evolution in Mesozoic Crocodyliformes, p. 84-97. In Fraser N.C. and Sues H.-D. (eds.), In the Shadow of the Dinosaurs: Early Mesozoic Tetrapods. Cambridge University Press, Cambridge and New York.

Colloca, F., Carpentieri, P., Balestri, E., and Ardizzone, G. 2010. Food resource partitioning in a Mediterranean demersal fish assemblage: the effect of body size and niche width. Marine Biology, 157:565-574.

Damuth, J. 1981. Population density and body size in mammals. Nature, 290:699-700.

Daudin, F.M. 1802. Histoire Naturelle, Générale et Particulière des Reptiles; ouvrage faisant suit à l'Histoire Naturelle générale et particulière, composée par LECLERC DE BUFFON; et rédigée par C. S. SONNINI, membre de plusieurs Sociétés savantes. Tome Second. F. Dufart, Paris.

Eudes-Deslongchamps, E. 1868. Note sur le squelette et la restauration du Teleosaurus cadomensis. Bulletin de la Société Linnéenne de Normandie, $2^{\mathrm{e}}$ série, 2:381-473.

Fanti, F., Miyashita, T., Cantelli, L., Mnasri, F., Dridi, J., Contessi, M., and Cau, A. 2016. The largest thalattosuchian (Crocodylomorpha) supports teleosaurid survival across the Jurassic-Cretaceous boundary. Cretaceous Research, 61:263-274.

Farlow, J.O., Hurlburt, G.R., Elsey, R.M., Britton, A.R.C., and Langston, J.W. 2005. Femoral dimensions and body size of Alligator mississippiensis estimating the size of extinct mesoeucrocodylians. Journal of Vertebrate Paleontology, 25:354-369.

Gaston, K.J. and Blackburn, T.M. 1996. Range sizebody size relationships: evidence of scale dependence. Oikos, 1996:479-485.

Gmelin, J.F. 1789. Caroli a Linné, Systema naturae per regna tria naturae, secundum classes, ordines, genera, species, cum characteribus, differentiis, synonymis, locis. Tomus 1 Pars 3. G.E. Beer, Lipsiae.

Godoy, P.L., Bronzati, M., Eltink, E., Marsola, J.C.A., Cidade, G.M., Langer, M.C., and Montefeltro F.C. 2016. Postcranial anatomy of Pissarrachampsa sera (Crocodyliformes, Baurusuchidae) from the Late Cretaceous of Brazil: insights on lifestyle and phylogenetic significance. PeerJ, 4:e2075. https://doi.org/ 10.7717/peerj.2075.
Hua, S. 1999. Le crocodilien Machimosaurus mosae (Thalattosuchua, Teleosauridae) du Kimmeridgien du Boulonnais (Pas de Calais, France). Palaeontographica Abteilung A, 252:141-170.

Hua, S. and Buffetaut, E. 1997. Crocodylia, p. 357-374. In Callaway, J.M. and Nicholls, E.L. (eds.), Ancient marine reptiles. Academic Press, San Diego.

Hutchinson, G.E. and MacArthur, R.H. 1959. A theoretical ecological model of size distributions among species of animals. American Naturalist, 93:117-125.

Johnson, M.M., Young, M.T., Steel, L., and Lepage, Y. 2015. Steneosaurus edwardsi (Thalattosuchia, Teleosauridae), the largest known crocodylomorph of the Middle Jurassic. Biological Journal of the Linnean Society, 115:911-918.

Krebs, B. 1968. Le crocodilien Machimosaurus. Memória dos Serviços Geológicos de Portugal (Nova Série), 14:21-53.

Kozlowski, J. and Gawelczyk, A.T. 2002. Why are species' body size distributions usually skewed to the right? Functional Ecology, 16:419-432.

Marsh, O.C. 1869. Notice of some new reptilian remains from the Cretaceous of Brazil. American Journal of Science, 47:390-392.

May, R.M. 1988. How many species are there on earth? Science, 241:1441-1449.

McClain, C.R. and Boyer, A.G. 2009. Biodiversity and body size are linked across metazoans. Proceedings of the Royal Society B: Biological Sciences, 276:2209-2215.

McDonald, R.A. 2002. Resource partitioning among British and Irish mustelids. Journal of Animal Ecology, 71:185-200.

Pierce, S.E. and Benton, M.J. 2006. Pelagosaurus typus Bronn, 1841 (Mesoeucrocodylia: Thalattosuchia) from the Upper Lias (Toarcian, Lower Jurassic) of Somerset, England. Journal of Vertebrate Paleontology, 26:621-635.

Peters, R.H. 1983. The ecological implications of body size. Cambridge University Press, Cambridge.

Pol, D., Leardi, J.M., Lecuona, A., and Krause, M. 2012. Postcranial anatomy of Sebecus icaeorhinus (Crocodyliformes, Sebecidae) from the Eocene of Patagonia. Journal of Vertebrate Paleontology, 32:328-354.

R Core Team. 2014. R: A language and environment for statistical computing. R Foundation for Statistical Computing, Vienna, Austria. URL http://www.R-project.org.

Ritz, C. and Spiess, A.-N. 2008. qpcR: an R package for sigmoidal model selection in quantitative real-time polymerase chain reaction series. Bioinformatics, 24:1549-1551.

Sauvage, H.-E. and Liénard, F. 1879. Memoire sur le genre Machimosaurus. Mémoires de la Société Géologique de France, 3ème série, 4:1-31.

Schneider, G. 1801. Historiae Amphibiorum naturalis et literariae. Fasciculus secundus continens Crocodilos, Scincos, Chamaesauras, Boas. Pseudoboas, Ela- 
pes, Angues. Amphisbaenas et Caecilias. Friederici Frommanni, Jena.

Sereno, P.C., Larsson, H.C.E., Sidor, C.A., and Gado, B. 2001. The giant crocodyliform Sarcosuchus from the Cretaceous of Africa. Science, 294:1516-1519.

Steel, R. 1973. Crocodylia. Handbuch der Paläoherpetologie, Teil 16. Gustav Fischer Verlag, Stuttgart.

van Valkenburgh, B., Wang, X., and Damuth, J. 2004. Cope's rule, hypercarnivory, and extinction in North American canids. Science, 306:101-104.

Vignaud, P. 1995. Les Thalattosuchia, crocodiles marins du Mésozoïque: Systématique, phylogénie, paléoécologie, biochronologie et implications paléogéographiques. Unpublished PhD dissertation, Université de Poitiers, Poitiers, France.

von Jäger, G.F. 1828. Über die fossile Reptilien, welche in Würtemberg aufgefunden worden sind. Verlag der J. B. Metzler'schen Buchhandlung, Stuttgart.

von Sömmerring, S.T. 1814. Über den Crocodilus priscus, oder ein in Baiern versteint gefundenes schmalkie-feriges Krokodil, Gavial der Vorwelt. Denkschriften der Königlichen Akademie der Wisseschaften zu München, 5: Classe der Mathematik und Naturwissenschaften, 9-82.

Westphal, F. 1962. Die Krokodilier des deutschen und englischen Oberen Lias. Palaeontographica Abteilung $A, 118: 23-118$.

Wilberg, E.W. 2015. What's in an outgroup? The impact of outgroup choice on the phylogenetic position of
Thalattosuchia (Crocodylomorpha) and the origin of Crocodyliformes. Systematic Biology, 64:621-637.

Woodward, A.R., White, J.H., and Linda, S.B. 1995. Maximum size of the Alligator (Alligator mississippiensis). Journal of Herpetology, 29:507-513.

Young, M.T. and Andrade, M.B. 2009. What is Geosaurus? Redescription of Geosaurus giganteus (Thalattosuchia, Metriorhynchidae) from the Upper Jurassic of Bayern, Germany. Zoological Journal of the Linnean Society, 157:551-585.

Young, M.T., Bell, M.A., Andrade, M.B., and Brusatte, S.L. 2011. Body size estimation and evolution in metriorhynchid crocodylomorphs: implications for species diversification and niche partitioning. Zoological Journal of the Linnean Society, 163:1199-1216.

Young, M.T., Brusatte, S.L., Andrade, M.B., Desojo, J.B., Beatty, B.L., Steel, L., Fernández, M.S., Sakamoto, M., Ruiz-Omeñaca, J.I., and Schoch, R.R. 2012. The cranial osteology and feeding ecology of the metriorhynchid crocodylomorph genera Dakosaurus and Plesiosuchus from the Late Jurassic of Europe. PLOS ONE, 7:e44985.

Young, M.T., Hua, S., Steel, L., Foffa, D., Brusatte, S.L., Thüring, S., Mateus, O., Ruiz-Omeñaca, J.I., Havlik, P., Lepage, Y., and Andrade, M.B. 2014. Revision of the Late Jurassic teleosaurid genus Machimosaurus (Crocodylomorpha, Thalattosuchia). Royal Society Open Science, 1:140222. http://rsos.royalsocietypublishing.org/content/1/2/140222 